\title{
HISTOPATHOLOGICAL STUDY OF ENDOMETRIUM IN POSTMENOPAUSAL BLEEDING
}

Arati Mallick$^{1}$, Ritanjali Behera² ${ }^{2}$ Khetrabasi Subudhi ${ }^{3}$

\section{HOW TO CITE THIS ARTICLE:}

Arati Mallick, Ritanjali Behera, Khetrabasi Subudhi. "Histopathological study of endometrium in postmenopausal bleeding". Journal of Evolution of Medical and Dental Sciences 2013; Vol. 2, Issue 46, November 18; Page: 9010-9018.

BACKGROUND: Postmenopausal bleeding is frequent in gynaecology and accounts approximately 5$10 \%$ of postmenopausal women. About $10 \%$ of women with postmenopausal bleeding have a primary or secondary malignancy. Common malignancies among them are endometrial cancer, cervical cancer or an ovarian cancer. The incidence of malignancy in postmenopausal period remains sufficiently high so it requires immediate investigation for early diagnosis, vigilant follow up and prompt treatment. AIMS \& OBJECTIVES: (1) To evaluate cause of Postmenopausal Bleeding (2) To detect early pre-cancerous lesions (atypia) \& endometrial hyperplasia (3) To confirm benign nature of problem by ruling out carcinoma, so that medical treatment or conservative surgery can be offered and unnecessary radical surgery can be avoided. MATERIALS \& METHODS: Study Design: Non-randomised longitudinal prospective observational study. Place of Study: Department Of Obstetrics \& Gynaecology, M.K.C.G Medical College \& Hospital, Berhampur, Odisha. Duration of Study: October 2010 -March 2012. Selection of Subjects: All patients having established menopause except those undergone hysterectomy/premature menopause ( $<40$ year)/on Hormone Replacement Therapy/on anticoagulant /having bleeding disorder included. Clinical \& histopathological details were collected \& analysed using mean \& standard deviation. RESULTS: Total 140 cases found during study period making the incidence of PMB to be 5.1\%.Mean age of PMB was $57.12 \pm 9.13$ years, Mean parity was 4.2 , Mean duration since menopause was $9.2 \pm 5.77$ years. Majority (52.86\%) had malignant cause \& $47.14 \%$ had benign cause. Overall most common cause found was cancer cervix(40\%) followed by endometrial carcinoma (9.28\%).Most common histopathology change in endometrium found was atrophic endometrium (40.74\%). DISCUSSION: 1) The incidence of PMB decreases with increasing age but the frequency of malignancy increased with increased age \& increased with increased interval between PMB \& menopause. 2) Diabetes, obesity \& hypertension are common medical illness in patients with PMB. These are risk factors for endometrial cancer. CONCLUSION: 1) Carcinoma of genital tract is one of the most important cause of PMB, so early detection of the causes can be life saving. 2) Endometrial sampling is a cost effective procedure to rule out endometrial carcinoma /detect in very early stage.

KEY WORDS: Menopause, Postmenopausal bleeding (PMB), Endometrium, Histopathology, Endometrial cancer.

INTRODUCTION: Postmenopausal bleeding (PMB) is defined as bleeding that occurs from the genital tract after one year of amenorrhoea, in a woman who is not receiving hormone replacement therapy (HRT) ${ }^{1}$ It may be heavy bleeding, just spotting or just like normal menstruation. ${ }^{2}$

The average age of menopause is 51 years. Even without amenorrhoea or irregularity, menstruation continuing after the age of 55 year should be investigated. Neither normal (functional) bleeding nor dysfunctional bleeding should occur after menopause. ${ }^{3}$ 


\section{ORIGINAL ARTICLE}

The approximate age of menopause is $49 \pm 3.6$ years. The proportion of women living to menopause and beyond has increased over the centuries with progressive increase in the life expectancy to approximately 82 years. As the women are spending increasing portion of their lives in menopause and thus postmenopausal problems are gaining more importance in gynaecological clinical practice. ${ }^{4}$

The commonest cause for bleeding occurring after menopause is the indiscriminate use of oestrogens for hormone replacement therapy. If this is excluded $10 \%$ of all patients and (30-50) \% of those in whom the bleeding is continuous or occurs more than once, are accounted for by malignant diseases of the cervix or of the body of the uterus. ${ }^{3}$ Women on continuous progesterone and oestrogen hormone replacement therapy can expect to have irregular vaginal bleeding, especially for the first six months. This bleeding should cease after one year. Women on oestrogen and cyclical progesterone should have a regular withdrawal bleeding after stopping the progesterone. Any unexpected bleeding or significant change in withdrawal bleeding should prompt further investigation. Women with abnormal postmenopausal bleeding include: 5

- Women with bleeding after one year of amenorrhoea

- Women with bleeding after one year of continuous combined HRT

- Women with unexpected bleeding while receiving cyclic HRT.

Postmenopausal vaginal discharge, which may be blood stained or purulent, is equally important like postmenopausal bleeding. Purulent vaginal discharge occurs in case of pyometra which is often seen in combination with endometrial cancer. ${ }^{6}$

A classic teaching has labeled postmenopausal bleeding as "Endometrial cancer until proven otherwise". Postmenopausal bleeding should always be investigated, because it could be a sign of endometrial carcinoma, which has a much higher cure rate if diagnosed early. Stage I endometrial carcinoma has a 5 year survival rate of $98 \%$, so early discovery greatly improves the chances of cure. It is estimated that postmenopausal women with vaginal bleeding have a probability of endometrial carcinoma of approximately $10 \% .^{7}$

The chances of postmenopausal bleeding decreases with increasing age but the frequency of malignancy is increased with increased age and increased with increased interval between postmenopausal bleeding and menopause. ${ }^{8}$

In women $>40$ years and certainly in postmenopausal patients, abnormal uterine bleeding mandates evaluation to confirm benign nature of the problem, by ruling out endometrial carcinoma, so that medical treatment or conservative surgery can be offered and unnecessary radical surgery can be avoided. ${ }^{9}$

\section{AIMS \& OBJECTIVES:}

\section{The present study proposes to:}

- To study histopathology of endometrium of women with postmenopausal bleeding to detect early precancerous lesions (atypia) and endometrial hyperplasia.

- To confirm the benign nature of the problem by ruling out endometrial carcinoma, so that medical treatment or conservative surgery can be offered and unnecessary radical surgery can be avoided. 


\section{ORIGINAL ARTICLE}

- To diagnose endometrial cancer in early stages so that timely treatment can be taken, this greatly improves chances of cure.

- Incidentally to evaluate the causes of postmenopausal bleeding.

MATERIAL \& METHODS: This non-randomized longitudinal prospective observational study, carried out on 140 women at the Department of Obstetrics \& Gynaecology, M.K.C.G. Medical College \& Hospital, Berhampur, Odisha, from October 2010-August 2012.

All postmenopausal women presenting through emergency or outpatient department, with complaint of bleeding per vaginum, with their last menstrual period 1 year back or who were $\geq 55$ years old were considered eligible for participation after informed consent, irrespective of their parity, social background, previous medical, surgical or gynaecological history. Patients having premature menopause (before 40 year age), surgical induced menopause, radiation induced menopause and chemotherapy induced menopause, those on HRT were excluded from the study. A full history of the patients was obtained. The name, age, parity, marital status (including husband name), address of the patients were noted. Details regarding vaginal bleeding were recorded. These included the timing of its onset, duration, colour and whether or not associated with passage of clots. History of associated symptoms included presence of any vaginal discharge, abdominal masses or distension, any accompanying abdominal pain or backache or a feeling of heaviness or something coming out of vagina. A history of recent weight loss or anorexia was noted as well as presence of any accompanying bowel or urinary symptoms. Treatments taken for the complaints were noted. Drug history especially that of HRT, tamoxifen was also noted. Information regarding obstetrical history was obtained. Gynaecological history included details about age at menarche and menopause, menstrual cycle, contraceptive history coital history (also about post coital bleeding) and details regarding cervical smears were recorded. ; Family history of carcinoma breast, carcinoma endometrium, carcinoma ovary, carcinoma colon. Past Medical and Surgical History was checked and questions regarding personal history were asked. A thorough general physical examination was performed with special attention to pallor, lymph nodes and breasts. Examination of the nervous system, cardiovascular system, respiratory system was performed in detail to look for any abnormal positive findings. Specific clinical examination including abdominal, speculum and bimanual pelvic examination was performed. Swabs were taken of any vaginal discharge and cervical smear was taken. Condition of the cervix and vaginal walls was noted. Bimanual examination was performed to assess the size, position and mobility of the uterus. Any adnexal heaviness was checked and presence of tenderness was noted. All patients had their blood group, haemoglobin, random blood sugar estimation, urine routine examination and coagulation profile. Xray chest and ECG was performed as a requirement of the anaesthesia department for all patients. Pelvic ultrasonography from the Radiology Department was arranged. The size position and, contours of the uterus were assessed. Endometrial thickness was measured for every case. Examination under anaesthesia was performed in special cases. . Endometrium obtained by Dilatation \& Curettage was subjected for histopathological examination in pathology department. Biopsy from any suspicious areas was taken. Endometrial polyps if present were avulsed and sent for histopathological examination. Incidentally causes of postmenopausal bleeding were also evaluated. Correlation of endometrial histopathological report was done with endometrial thickness previously obtained with ultrasound, with other pathologies and other external factors like oral 
contraceptive pill use, obesity, effect of systemic diseases like hypertension and diabetes was done. The final diagnosis of each woman was made on the curettage specimen and resected material or hysterectomy specimen when present.

Addresses of the patients were carefully recorded so that they could be contacted

STATISTICAL METHODS: The statistical methods used in the study were:

- Sensitivity and Specificity

- Positive Predictive Value (PPV) and

- Negative Predictive Value (NPV)

- Mean

- Standard Deviation(SD)

RESULTS: During the period of this study a total number of 140 consecutive patients who met inclusion criteria were enrolled in the study. The incidence of PMB was found to be $5.1 \%$ of all gynaecologic patients.

\begin{tabular}{|c|c|c|}
\hline Age Group (Years) & Number & Percentage \\
\hline $41-45$ & 8 & 5.71 \\
\hline $46-50$ & 24 & 17.14 \\
\hline $51-55$ & 38 & 27.15 \\
\hline $56-60$ & 26 & 18.57 \\
\hline $61-65$ & 23 & 16.43 \\
\hline$>65$ & 21 & 15.00 \\
\hline Total & 140 & 100.00 \\
\hline \multicolumn{3}{|c|}{$\begin{array}{l}\text { Table-1: AGE INCIDENCE IN } \\
\text { POSTMENOPAUSAL BLEEDING }\end{array}$} \\
\hline
\end{tabular}

Ages of patients with postmenopausal bleeding ranged between 43 years and 80 years with a mean age of $57.12 \pm 9.13$ years. The maximum number of cases $38(27.15 \%)$ were between the age group 51 and 55.

Parity of cases ranged from $\mathrm{P}_{0}-\mathrm{P}_{11}$ (mean parity 4.2). The majority of patients, 64 (45.72\%) had parity of 3-4. Five (3.57\%) patients were nulliparous. 48 (34.28\%) were grand multiparous having parity $\geq 5$, showing association of high parity among the patients of PMB.

Age at menarche of patients who presented with postmenopausal bleeding ranged from 1117 years. The mean age of menarche was $13.23 \pm 1.66$ years. The majority of patients $79(56.43 \%)$ had menarche at 13-15 year of age.

The current study reveals that the age at menopause ranged from 42 years to 57 years. Mean age of menopause was $48.06 \pm 5.1$ years. The maximum number of patients $63(45 \%)$ had menopause between 46-50 years. Eight (5.71\%) patients had menopause at a later age of $\geq 56$ years. The period between menopause and onset of postmenopausal bleeding ranged from 1 year to 29 years. Majority of patients 51 (36.43\%) had >5-10 years period between menopause and onset of symptom. The mean duration since menopause was $9.2 \pm 5.77$ years. The table clearly shows the incidence of PMB gradually decreases with increased interval of bleeding onset and menopause. 
Along with PMB, the commonest associated symptom was vaginal discharge. Pain lower abdomen and low back-ache were the second most common associated symptoms.

Patients presenting with postmenopausal bleeding were divided into three groups according to the amount of vaginal bleeding. Bleeding was categorized as Mild / Scanty, if blood loss was less than that occurs during normal menstruation. Moderate if it was similar to that which occurs during normal menstruation. Severe if it was more than that which occurs during normal menstruation. Regarding the amount of per vaginal bleeding, majority 72 (51.43\%) had scanty/mild bleeding while $56(40 \%)$ had presented with moderate bleeding and only $9(6.43 \%)$ patients had severe per vaginal bleeding at presentation.Three (2.14\%) patients had only spotting.

Maximum 54 (38.57\%) patients had Endometrial Thickness between 4-6 mm. Endometrial thickness of the current studied cases ranged from $2 \mathrm{~mm}-24 \mathrm{~mm}$. The mean thickness was $5.45 \pm$ $2.97 \mathrm{~mm}$.

\begin{tabular}{|c|c|c|c|}
\hline \multicolumn{2}{|c|}{ Histopathological Report } & No. of Cases & Percentage \\
\hline \multirow{3}{*}{ Hyperplasia } & Simple & 9 & 8.34 \\
\hline & Complex & 4 & 3.70 \\
\hline & Atypical & 1 & 0.93 \\
\hline \multicolumn{2}{|c|}{ Endometrial Carcinoma } & 14 & 12.96 \\
\hline \multicolumn{2}{|c|}{ Ca. Cervix showing Endometrial invasion } & 5 & 4.63 \\
\hline \multicolumn{2}{|c|}{ Atrophic } & 44 & 40.74 \\
\hline \multicolumn{2}{|l|}{ Proliferative } & 14 & 12.96 \\
\hline \multicolumn{2}{|l|}{ Secretary } & 4 & 3.70 \\
\hline \multicolumn{2}{|l|}{ Endometrial polyp } & 5 & 4.63 \\
\hline \multicolumn{2}{|l|}{ Endometritis } & 4 & 3.70 \\
\hline \multicolumn{2}{|c|}{ Tubercular endometritis } & 1 & 0.93 \\
\hline \multicolumn{2}{|c|}{ Tissue inadequate for diagnosis } & 3 & 2.78 \\
\hline \multicolumn{2}{|c|}{ Total } & 108 & 100.00 \\
\hline
\end{tabular}

D \& C was done in 108 (77.14\%) patients and couldn't be done in 32 number of patients due to cervical stenosis.

Malignancy was more frequent found in74 out of 140 cases (52.86\%). Cervical cancer comprises for maximum number of cases i.e. 56 (40\%) of total, Carcinoma endometrium in 13 patients (9.28\%) \&Carcinoma ovary comprised of 5 (3.57\%) patients of the total.

In the current study, the mean age of endometrial cancer found was 67 years and the youngest patient in that age group was 60 years old. While cervical cancer had mean age of 56 years and the youngest patient was 44 years old.

Benign pathology was found in $64(45.71 \%)$ patients of total cases. Atrophic endometritis was the commonest benign cause comprising total $25(17.85 \%)$ cases. Endometrial hyperplasia in $14(10 \%)$ including atypical hyperplasia in 1 case $(0.93 \%)$, endometrial polyp found in $5(3.57 \%)$, cervical polyp in $2(1.43 \%)$, senile vaginitis in $3(2.14 \%), 5$ cases $(3.57 \%)$ had PMB due to decubitus ulcer associated with uterovaginal prolapse. Myoma constituted $8(5.71 \%)$ and $2(1.43 \%)$ cases of 


\section{ORIGINAL ARTICLE}

adenomyosis were found. One cases of each Genital Tuberculosis and Endometrial Stromal Nodule found.

DISCUSSION: Postmenopausal bleeding is frequent in gynaecology and accounts approximately 3\% of postmenopausal women. ${ }^{10}$ This symptom can reveal benign causes as well as cancers. The primary aim is to identify and exclude atypical hyperplasia and endometrial carcinoma. The risk of endometrial carcinoma in women with postmenopausal bleeding rises with age from $1 \%$ at the age of 50 years to approximately $25 \%$ at the age of 80 years. ${ }^{11}$

Ages of patients with postmenopausal bleeding in the current study ranged between 43 years and 80 years with a mean age of $57.12 \pm 9.13$ years. This age is much lower than the mean age 64 year by Kour M et al (2010) ${ }^{12}$ and 63.6 year by Nasira Sabiha Dawood et al (2010) ${ }^{13}$.The lower mean age in our study group may be due to higher incidence of cervical carcinoma which has early age of presentation.

It has been reported that the incidence of PMB decreases with increasing age ${ }^{11}$. This study also proved the same. 87 (62.5\%) cases of postmenopausal bleeding were between 51 and 60 years of age, while only 21 cases (15\%) were above 65 years of age.

Early marriage, early child bearing, high parity, illiteracy \& poor socioeconomic status are all high risk factors for cervical cancer. 48 patients (34.28\%) were having parity $\geq 5.110$ (78.57\%) patients were either illiterate or less than high school passed, 79 (56.43\%) of total belonged to poor socioeconomic status, maximum cases were from Rural area, constituting 99 (70.72\%) of total.

In a recently conducted study, it was reported that post-menopausal women with vaginal bleeding have a probability of endometrial carcinoma of approximately $9 \% 14$. Sadia Zulfiquar Cheema et al (2008) ${ }^{15} \&$ M.C.Breijer et al (2010) ${ }^{16}$ reported the incidence of endometrial cancer to be $10 \%$ in cases of PMB. Here this probability was $9.28 \%$ (13 cases out of 140 ).

Nulliparity, early menarche, chronic anovulation, late menopause, unopposed endogenous and exogenous oestrogens and Tamoxifen therapy have all been proven to be risk factors for the development of endometrial hyperplasia and carcinoma. ${ }^{17}$ Here out of the total 13 cases of endometrial carcinoma 2 cases were nulliparous, 8 cases had low parity $\left(\mathrm{P}_{1}-\mathrm{P}_{2}\right) .6$ cases had early menarche (before 12 years of age) and 7 cases had late menopause (after 51 years of age).

Likewise obesity, diabetes mellitus and hypertension have been associated with endometrial carcinoma. In the present study, out of 13 cases of endometrial carcinoma 8 cases had BMI>30 $\mathrm{kg} / \mathrm{m}^{2}$, hypertension in 10 cases and diabetes mellitus in 9 cases.

Tamoxifen therapy in the treatment or prevention of breast cancer increases the risk of endometrial cancer 3-6 fold ${ }^{18}$.In the present study out of 13 cases only one case was having breast cancer and was on long term tamoxifen treatment, diagnosed as endometrial carcinoma.

The specificity of D\&C was $100 \%$, positive predictive value was $100 \%$ and negative predictive value was $98.95 \%$.It is consistent with study by Aiza Saadia et al (2011) ${ }^{19}$, where the positive predictive value and specificity of endometrial curettage in diagnosing endometrial cancer found was $100 \%$ and negative predictive value was $93.1 \%$.

Endometrial hyperplasia is an oestrogen dependent condition and has the same risk factors as for endometrial carcinoma. The complex atypical hyperplasia has $25-30 \%$ incidence of progression to invasive carcinoma while simple hyperplasia has only $1 \%$ incidence of progression. 


\section{ORIGINAL ARTICLE}

Women with simple hyperplasia respond to hormonal treatment like levonorgestrol IUS 20 but with atypical hyperplasia should be offered total hysterectomy. ${ }^{21}$

The assessment and investigations of cases of PMB is moving away from the operation theatre and ward environment into the outpatient department. The primary assessment in all cases of postmenopausal bleeding should be with transvaginal ultrasound scanning (TVS), as the thickening of the endometrium may indicate the presence of significant pathology (e.g. endometrial cancer). ${ }^{22}$ Endometrial evaluation among postmenopausal women is a topic of ongoing debate in the literature. There is a trend towards investigating intracavitary uterine lesions only with postmenopausal bleeding when the endometrial thickness, as measured by ultrasound is $>4 \mathrm{~mm}^{23}$. Other authors have recommended systemic collection of biopsies from symptomatic patients 24 regardless of endometrial thickness, because of reports of cancer in patients presenting ultrasoundmeasured endometrial thickness $\leq 5 \mathrm{~mm}{ }^{25}$.

The incidence of malignancy in postmenopausal period remains sufficiently high so it requires immediate investigation for early diagnosis, vigilant follow up and prompt treatment. It is difficult to predict the population changes in future, but it is certain that we are going to see an everincreasing number of postmenopausal women day by day. In real terms there are more women who are spending a greater proportion of their lives in the postmenopausal years. The result of this study doesn't show the dramatic decrease in the prevalence of malignancy as a cause of postmenopausal bleeding seen in South Odisha. The famous dictum that "Postmenopausal bleeding must be considered as indicative of malignant disease until proven otherwise" still holds true in our circumstance. Malignancy was the major cause comprising $52.86 \%$ cases which is more than half of total cases, indicates an alarming sign for the Gynaecologists to evaluate the postmenopausal bleeding cases more thoroughly and promptly. Endometrial biopsy should be undertaken in all postmenopausal women with endometrial thickness (E.T) greater than $4 \mathrm{~mm}$ or persistent bleeding despite a normal E.T. ${ }^{26}$

The reason for high rate of malignancy as a cause of PMB in developing countries compared to developed world might be lack of accessibility for modern health care, the absence of screening method such as Pap smear for detection of precursor lesion of cervical cancer in the former countries. Among the malignant lesions, the incidence of carcinoma cervix and carcinoma endometrium varied in different studies. Studies from India show high incidence of carcinoma cervix than carcinoma endometrium in PMB cases.

Most patients of malignant disease were of carcinoma cervix comprising $75.68 \%$ of the total malignant causes and $40 \%$ of the total cases studied as a overall cause, which is almost one in every four patients. Most patients were at stage-IIIB at the time of examination. This high incidence may point to ineffectiveness of existing surveillance and the need for public awareness to integrate routine gynaec Pap screening as a routine method. Cervical malignancies must be ruled out in all cases of postmenopausal bleeding. Priority should be given to introduce screening methods for cervical cancer such as cervicography, gynoscopy and Pap smears at different levels of health care to effectively reduce the prevalence of cervical cancer among elder women. In addition, the significant contribution of cervical cancer as a cause of postmenopausal bleeding and its prevention should be brought into the public awareness. Low literacy status, poor socioeconomic status with poor personal hygiene and higher order of childbirth are all risk factors for cervical carcinoma. These all 


\section{ORIGINAL ARTICLE}

factors should be taken care in a team effort of government and medical persons to reduce cervical carcinoma incidence and to detect it at a treatable early/precancerous stage.

\section{REFERENCES:}

1. Brand AH. The woman with postmenopausal bleeding. Australian Family Physician 2007; 30:97-192.

2. Khan RL. Postmenopausal bleeding. In text book of Gynaecology, $3^{\text {rd }}$ edition. Medical Publications, Lahore 2000; 260-262.

3. Jeffcoates Principles of Gynaecology, $7^{\text {th }}$ Edn; 613-614.

4. Monagham JM. Operation on the uterine cavity. In Monagham JM (ed) Bonney' Gynaecological Surgery,9 $9^{\text {th }}$ Edn. East. Sussex, Baillire Tindall 1986; 40-43.

5. Brdley LD, Franalcone T, Magen AB. Radiographic Imaging techniques for the diagnosis of abnormal uterine bleeding. Obstet Gynaecol 2000; 27:245-277.

6. Wilailak S, Jhirapinyo M, Theppisai U. Transvaginal Doppler Sonography: Is there a role of this modality in the evaluation of women with postmenopausal bleeding. Maturitas 2005; 50:1116.

7. Smith Bindman R, Kerlikows Ke K, Feldstein VA et al. Endovaginal Ultrasound to exclude endometrial cancer and other abnormalities. JAMA 1998; 280:1510-17.

8. Asim SS,Akhter AZ.Frequency of women with postmenopausal bleeding.ANN Abbasi Shaheed Hospital,Karachi Med Dent College,Jun. 2004;9 (1):506-509.

9. Golden stein SR.Modern evaluation of endometrium.Obstet Gynaecol.2010;116:168-76.

10. Anon, Endometrial bleeding. Hum Reprod Update 2007; 13: 421-31.

11. Gredmark T, Kvint S, Havel G, Mattsson LA. Histo-pathological findings in women with postmenopausal bleeding. Br J Obstet Gynaecol 1995; 102: 133-36.

12. Kaur M,Singh R,Sharma M.Endovaginal Sonographic Evaluation of Postmenopausal Uterine Bleeding.J.of Clinical and Diagnostic Research,April 2010;4:2175-82.

13. Naseera Sabiha Dawood, Kiran Peter, Faiza Ibrar et al. Postmenopausal bleeding: Causes and risk of genital tract malignancy. J Ayub Med Coll Abbottabad 2010; 22 (2): 117-120.

14. I Bani- Irshaid, A AF-Sumadi. Histological findings in women with postmenopausal bleeding in Jordan Women. East Mediterr Health J 2011 Jul; 17 (7): 582-6.

15. Dr Sadia Zulfiqar Cheema, Dr Roohi Saheed, Dr Muhammad Ikram, Prof. Muhammad Saheed. Postmenopausal bleeding. Professional Med J Sept 2008; 15 (3): 328-334.

16. M.C. Breijer, A. Timmermans, H.C. Van Doorn, B.W. J. Mol, B.C. Opmeer. Diagnostic strategies (Histopathological assessment) for postmenopausal bleeding. Obstet Gynaecol International 2010; 812-850.

17. Brinton LA, Berman ML et al 1992. Reproduction men-strual and medical risk factors for endometrial cancer. Am J Obstet Gynecol 1992; 167: 1317-25.

18. Rutquist LE, Johansson H, Signomklao T, Johansson U, Fornander T, Wilking N.Adjuvant Tamoxifen therapy for early stage breast cancer and second primary malignancies. Stockholm Breast Cancer Study Group. J Natl Cancer Inst 1995;87: 645-51.

19. Aiza Saadia, Azher Mubarik, Alia Zubair, Shahid Jamal, Ambreen Zafar. Diagnostic accuracy of endometrial curettage in endometrial pathology. J Ayub Med Coll Abbottabad 2011; 23 (1): 129-131. 


\section{ORIGINAL ARTICLE}

20. Wildemeersch D, Janssens D, Pylyser K et al. Manage-ment of patients with non-atypical and atypical endometrial hyperplasia with a levonorgestrel - releasing intrauterine system: longterm follow-up. Maturitas 2007; 57: 210-13.

21. Horn LC, Schnurrbusch U, Bilek K, Hentschel B, Eine-nkel J. Risk of progression in complex and atypical endometrial hyperplasia: clinicopathological analysis in cases with and without progestogen treatment. Int J Gynecol Cancer 2004; 14: 348-53.

22. Wolman I, Amster R, Hartoov J et al. Reproducibility of transvaginal ultrasonographic measurements of endometrial thickness in patients with postmenopausal bleeding.Gynecol Obstet Invest 1998; 46: 191-94.

23. Birinyi L,Darago $P$,Torok $P$ et al.Predictive value of hysteroscopic examination in intrauterine abnormalities.Eur J Obstet Gynecol Reprod Biol.2004;115 (1):75-79.

24. Tabor A,Watt HC,Wald NJ.Endometrial thickness as a test for endometrial cancer in women with postmenopausal bleeding.Obstet Gynecol.2002; 99 (4):663-70.

25. Litta P, Merlin F, Saccardic C, et al.Role of hysteroscopy with endometrial biopsy to rule out endometrial cancer in postmenopausal women with abnormal uterine bleeding.Maturitas.2005;50 (2):117-23.

26. Goldenstein RB,Bree RL,Benson CB,et al.Evaluation of the woman with postmenopausal bleeding:Society of Radiologists in Ultrasound sponsored consensus conference statement.J. Ultrasound Med 2001;10:1025-36.

\section{AUTHORS:}

1. Arati Mallick

2. Ritanjali Behera

3. Khetrabasi Subudhi

\section{PARTICULARS OF CONTRIBUTORS:}

1. Junior Resident (Post Graduate), Department of Obstetrics \& Gynaecology, M.K.C.G. Medical College \& Hospital, Berhampur, Odisha.

2. Associate Professor, Department of Obstetrics \& Gynaecology, M.K.C.G. Medical College \& Hospital, Berhampur, Odisha.

3. Professor \& Head, Department of Obstetrics \& Gynaecology, M.K.C.G. Medical College \& Hospital, Berhampur, Odisha.

\section{NAME ADDRESS EMAIL ID OF THE CORRESPONDING AUTHOR: \\ Dr. Arati Mallick, C/O - Dr. Balkrishna Kuanar, Gayatri Vihar, 28-Cantenment Road, Chandi Chhak, Buxibazar, Cuttack, Odisha - 753001. \\ Email - draratimallick@gmail.com}

Date of Submission: 30/10/2013.

Date of Peer Review: 31/10/2013.

Date of Acceptance: 09/11/2013.

Date of Publishing: 14/11/2013 